\title{
CPITN Index and Subjective Complaints after Treatment with Fixed Dental Prostheses
}

\author{
Desislava Konstantinova, Anna Nenova-Nogalcheva
}

\begin{abstract}
It is not uncommon in dental practice to observe inflammatory destructive periodontal disease after treatment with fixed prosthetic constructions. The aim of the present study was to determine the role of pre-prosthetic periodontal treatment in view of patients' increasing subjective complaints and the need for periodontal treatment. Material for the study were 116 patients. Among documented subjective symptoms were sensitivity to cold food/drinks, spontaneous periodontal bleeding and fetor oris. The objective periodontal changes were assessed with the CPITN index. The results revealed that 1 year after prosthetic treatment $26.67 \%$ of patients in Group 2, who had undergone only initial therapy, reported sensitivity to cold, and by the third year the affected patients increased to 46.67\%. There was a statistically significant correlation $(P<0.0001)$ between the periodontal status and the pre-prosthetic periodontal treatment. Conclusions: The lack of pre-prosthetic periodontal treatment can be evaluated as a risk factor in the restoration with fixed dental prostheses.
\end{abstract}

Keywords: CPITN index, fetor oris, periodontal bleeding, sensitivity to cold

\section{Introduction}

Periodontitis is defined as inflammatory diseases of teeth supporting structures, generally caused by microorganisms in the dental plaque and characterized by a progressive destruction of the periodontal ligament and alveolar bone, inflammation of the periodontal pocket and gingival recession [1]. Periodontal treatment is largely intended to limit and stop bone loss and control the quantity and quality of supra- and subgingival biofilm as well as to establish a microflora compatible with a healthy periodontium. Quite often following a prosthetic treatment the periodontium may be compromised due to the crown edge position [2]. WHO supports the application of the CPITN index as an epidemiological screening procedure for periodontal treatment needs for population groups and also as a modified form of screening and monitoring of patients by dental clinicians $[3,4,5,7]$.

\section{Aim}

The objective of the present study was to determine the role of pre-prosthetic periodontal treatment in view of patients' increasing subjective complaints and the need for periodontal treatment.

\section{Material and Methods}

The material of the study were 116 patients (59 women and 57 men), whose medical history was taken. The patients then had extra- and intraoral examinations as well as diagnostic imaging performed. Their periodontal status was assessed with the CPITN index. (Table 1)
Table 1: Classification as per Shah [4]

\begin{tabular}{|c|c|c|}
\hline Clinical picture & Result & Treatment needs \\
\hline No present disease & 0 & No treatment needed \\
\hline $\begin{array}{c}\text { Gingival bleeding on } \\
\text { probing }\end{array}$ & 1 & $\begin{array}{c}\text { A need for improving the oral } \\
\text { hygiene (TN1) }\end{array}$ \\
\hline $\begin{array}{c}\text { Supragingival and/or } \\
\text { subgingival calculus }\end{array}$ & 2 & $\begin{array}{c}\text { A need for improving the oral } \\
\text { hygiene and scaling (TN2) }\end{array}$ \\
\hline $\begin{array}{c}\text { Pathological pocket } \\
\text { depth (4 -5 mm) }\end{array}$ & 3 & $\begin{array}{c}\text { A need for improving the oral } \\
\text { hygiene and scaling (TN2) }\end{array}$ \\
\hline $\begin{array}{c}\text { Pathological pocket } \\
\text { depth ( }>6 \mathrm{~mm} \text { ) }\end{array}$ & 4 & $\begin{array}{c}\text { A need for improving the oral } \\
\text { hygiene, scaling and a complex } \\
\text { periodontal treatment }\end{array}$ \\
\hline
\end{tabular}

Group 1, consisting of 56 patients (30 women and 26 men), had underwent pre-prosthetic treatment in the form of open flap curettage, surgical crown lengthening procedure by gingivectomy or apically positioned flap surgery (APF), correcting gingival recession of one or several teeth. Some patients had bone-grafting procedure to improve the level of the bone. Group 2 patients (60 patients - 32 women and 28 men) had only initial therapy. All patients were monitored at 4 follow-up checks: within 7 days after completion of prosthetic treatment, after 1 year, after 3 years and after 5 years. Among documented subjective symptoms were sensitivity to cold food/drinks, spontaneous periodontal bleeding and fetor oris.

The statistical analysis of the results obtained was performed using SPSS Statistics software package for epidemiological and clinical research (V.16.00, Nov. 2007).

\section{Results}

The results obtained within 1 week of completion of prosthetic treatment showed no subjective complaints in the participants in either group under study. However, after 1 year, Group 2 patients exhibited periodontal changes, manifested in sensitivity to cold, spontaneous periodontal bleeding and halitosis. (Figures 1, 2, 3) 
International Journal of Science and Research (IJSR)

ISSN (Online): 2319-7064

Index Copernicus Value (2015): 78.96 | Impact Factor (2015): 6.391

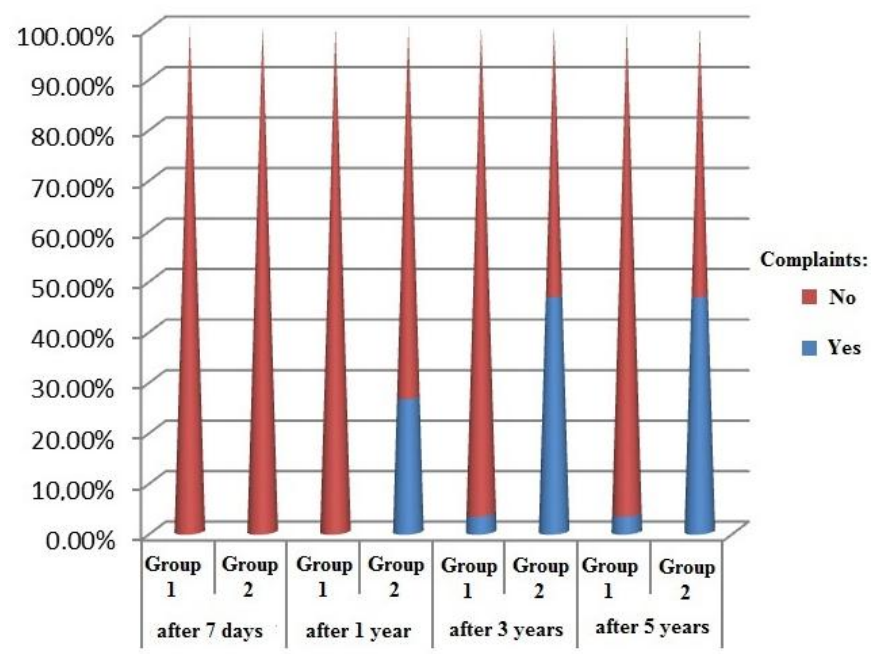

Figure 1: Percentage distribution of patients according to the presence/absence of sensitivity to cold in both groups

The observations revealed that 1 year after prosthetic treatment $26.67 \%$ of patients in Group 2 reported sensitivity to cold and by the 3rd year their complaints increased to $46.67 \%$. Only $3.57 \%$ of patients in Group 1 showed sensitivity to cold after the 3rd year.

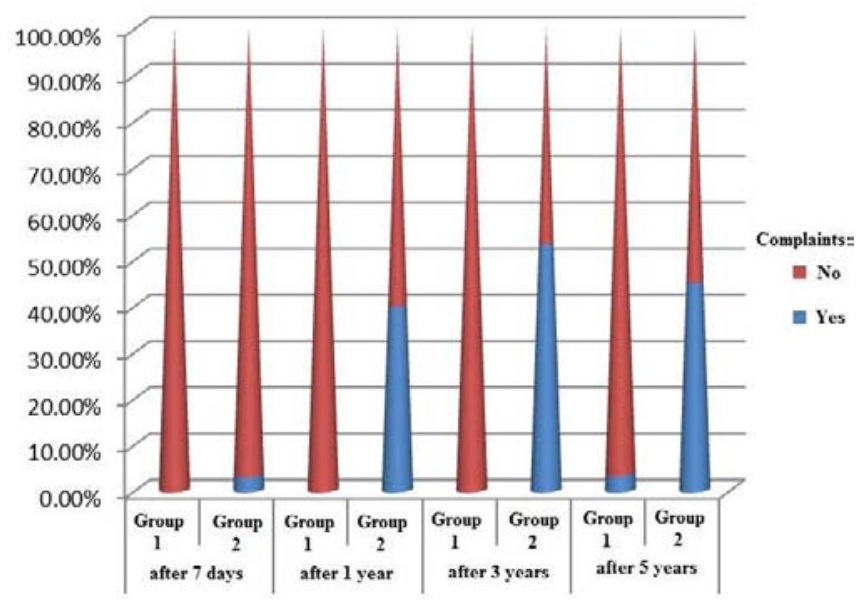

Figure 2: Percentage distribution of patients according to the presence/absence of spontaneous gum bleeding in both groups

Periodontal bleeding is a poor prognostic sign for the state of the periodontium. At the first follow-up check $3.33 \%$ of patients in Group 2 reported gum bleeding, 40\% - after 1 year, and an alarming $53.33 \%$ - after 3 years. (Figure 3 ) Only a small number of Group 1 patients (3.57\%) had bleeding gums complaint after 5 years.

Similar results were obtained regarding participants' complaints of bad breath (halitosis). Only one patient from Group $1(3.57 \%)$ reported fetor oris after 5 years, whereas the proportion distributions in Group 2 were as follows: $33.33 \%$ - after 1 year, $50 \%$ - after 3 year and up to $60 \%$ after 5 years. (Figure 4 )

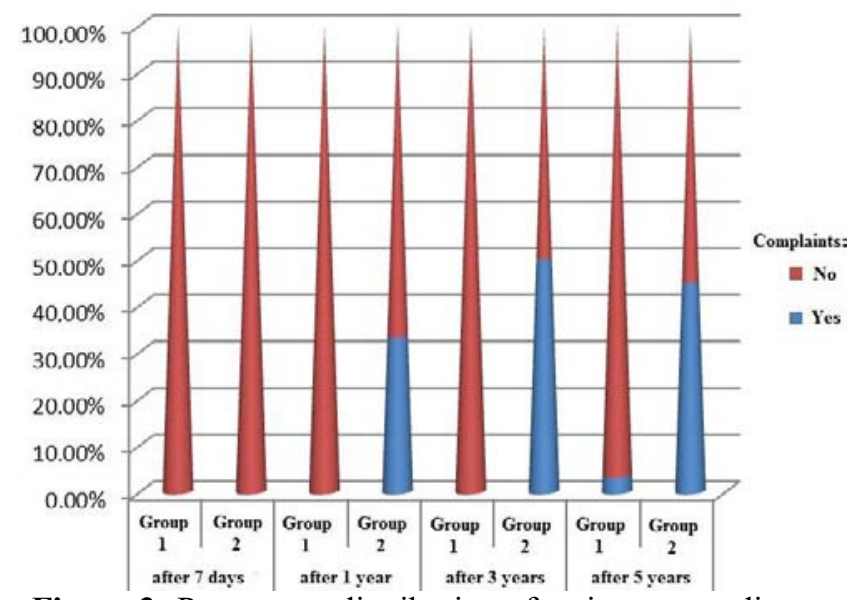

Figure 3: Percentage distribution of patients according to the presence/absence of fetor oris in both groups

Table 2: Distribution of patients according to their periodontal status and pre-prosthetic treatment

\begin{tabular}{|c|c|c|c|c|}
\hline \multirow{2}{*}{\multicolumn{2}{|c|}{$\begin{array}{l}\text { A NEED FOR } \\
\text { PERIODONTAL } \\
\text { TREATMENT }\end{array}$}} & \multicolumn{2}{|c|}{$\begin{array}{l}\text { PRE-PROSTHETIC } \\
\text { TREATMENT }\end{array}$} & \multirow{3}{*}{$\begin{array}{c}\begin{array}{c}\text { Total } \\
\text { number }\end{array} \\
57\end{array}$} \\
\hline & & \multirow{2}{*}{\begin{tabular}{|c|} 
NO \\
2 \\
\end{tabular}} & \multirow{2}{*}{$\begin{array}{c}\text { YES } \\
55\end{array}$} & \\
\hline & number & & & \\
\hline PIIIN CUDE 0 & $\%$ v & $3.51 \%$ & $96.49 \%$ & $100.0 \%$ \\
\hline \multirow{2}{*}{$\begin{array}{l}\text { CPITN CODE } 1 \\
\text { or CODE } 2\end{array}$} & num & 50 & 1 & \\
\hline & $\% \mathrm{n}$ & $98.04 \%$ & $1.96 \%$ & $100.0 \%$ \\
\hline \multirow{2}{*}{$\begin{array}{l}\text { CPITN CODE } 3 \\
\text { or CODE } 4\end{array}$} & & 8 & 0 & \\
\hline & & $100 \%$ & $0 \%$ & \\
\hline \multirow{2}{*}{ Total number } & & 60 & 56 & \\
\hline & $\%$ within row & $51.73 \%$ & $48.27 \%$ & $100.0 \%$ \\
\hline
\end{tabular}

Table 2 displays a statistically significant correlation $(\mathrm{P}<0.0001)$ between patients' periodontal status and the preprosthetic periodontal treatment. (Figures 4a, 4b, 5a, 5b) The observations revealed that the patients with healthy periodontium (Code 0) and those who had undergone prior periodontal treatment $(96.49 \%)$ proved to be by far more than the patients without any prior treatment.

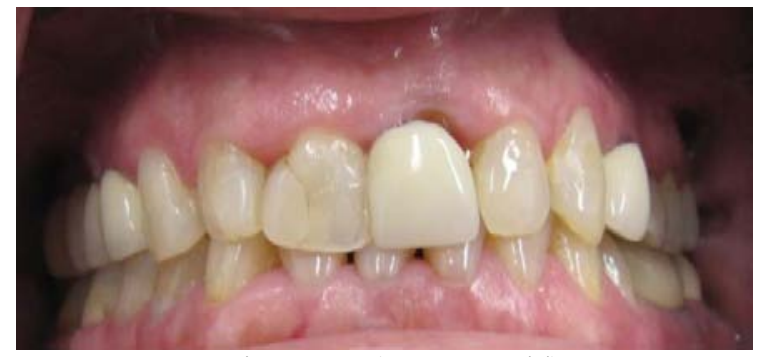

Figure 4(a): Patient V.G (54 years old), Group 2 - an intraoral examination prior to prosthetic treatment

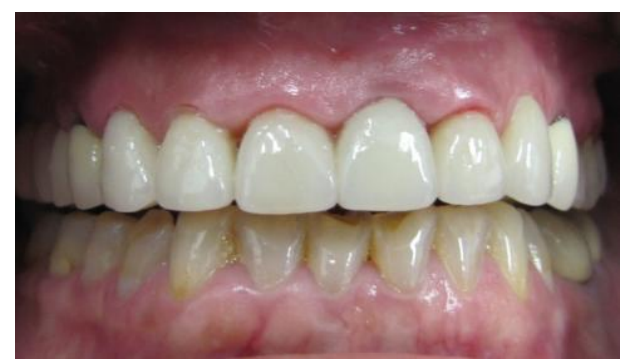

Figure 4(b): Patient V.G. (54 years old), Group 2 - an intraoral examination 3 years after prosthetic treatment 


\section{International Journal of Science and Research (IJSR) \\ ISSN (Online): 2319-7064 \\ Index Copernicus Value (2015): 78.96 | Impact Factor (2015): 6.391}

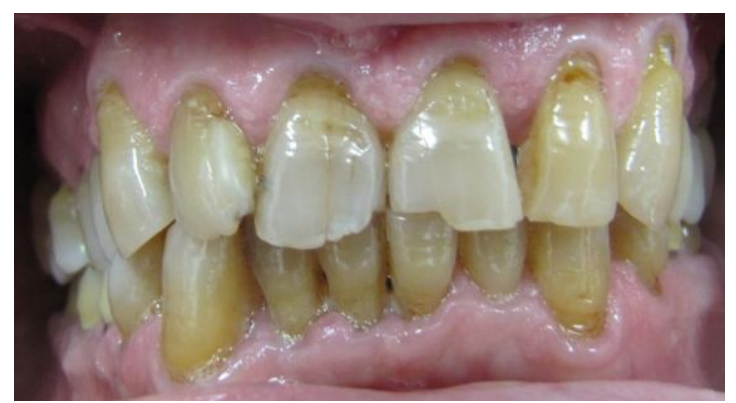

Figure 5(a): Patient V.V. (72 years old), Group 1 - an intraoral examination prior to prosthetic treatment

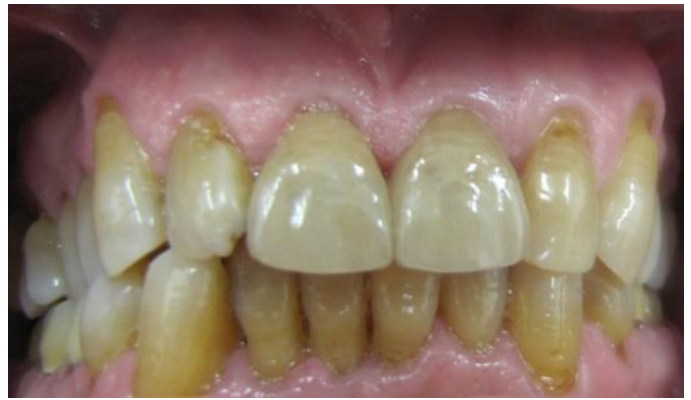

Figure 5(b): Patient V.V. (72 years old), Group 1 - an intraoral examination 3 years after prosthetic treatment

\section{Discussion}

Patients' subjective complaints are indicative for the success in the rehabilitation of the masticatory apparatus. The present study analyzed the subjective symptoms which brought the patients back to the dental clinician for further treatment. The comparative analysis of subjective complaints, objectively assessed with the CPITN index, revealed a statistically significant correlation $(\mathrm{P}<0.0001)$. Pre-prosthetic periodontal treatment proves essential in the prognostic factors for treatment success $[8,9]$.

\section{Conclusions}

The lack of periodontal treatment can be evaluated as a risk factor for the treatment with fixed dental prostheses. In that case the prosthetic treatment is likely to lead to early subjective complaints of patients and the need of treatment according to the CPITN index.

\section{References}

[1] Mlachkova A, Popova ChL. Dental Investigations: Efficiency of Nonsurgical Periodontal Therapy in Moderate Chronic Periodontitis. Folia Medica; 2014, 56, Issue 2, pp. 109-115.

[2] Nyman S, Lindhe J. A Longitudinal Study of Combined Periodontal and Prosthetic Treatment of Patients with Advanced Periodontal Disease. Journal of Periodontology; 1979, 50, 4, 163-169, DOI 10.1902/jop.1979.50.4.163 (doi:10.1902/jop.1979.50.4.163).

[3] Cutress TW, Ainamo J, Sardo-Infirri J. The community periodontal index of treatment needs (CPITN) procedure for population groups and individuals. International Dental Journal; 1987, 37(4):222-233.
[4] Shah CS. An epidemiological study in Gujarat by community periodontal index of treatment needs (CPITN). Annals and Essences of Dentistry; 2010;2(4):30- 32.

[5] Miyazaki H, Pilot T, Leciercq MH, Barmes DE. Profiles of periodontal conditions in adolescents measures by CPITN. Int. Denta. J. 1991; 41:67 - 73.

[6] Butterworth M, Sheiham A. Changes in the Community Periodontal Index of Treatment Needs (CPITN) after periodontal treatment in a general dental practice. Br. Dent. J. 1991; 171:363-366.

[7] Sheiham A. Public health aspect of periodontal disease in Europe. J. Clin Periodontal. 1991; 18:362-369.

[8] Hsu YT, Huang NC, Wang HL. Relationship between Periodontics and Prosthodontics: The two-way street. Journal of Prosthodontics and Implantology. 2015, volume 4, 4-11.

[9] Uhač I, Kuiš D, Kavčič R, Lajnert V, Šoškić MŠ, et all. Fixed prosthodontic restorations and periodontal health. Medicina Fluminensis. 2014; 50(3): 279-287.

\section{Author Profile}

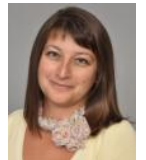

Dr. Desislava Konstantinova obtained her Master's degree in Dentistry in 1997 from the Medical University -Plovdiv. She has been working as an Assistant Professor at the Prosthetic Dentistry Department at the Medical University -Varna since 2008. She specialized in Prosthetic Dentistry in 2106 and was awarded a PhD degree in 2016.

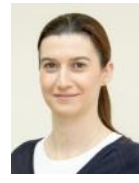

Dr. Anna Nenova-Nogalcheva obtained her Master's degree in Dentistry in 2006 from the Medical University - Plovdiv, Bulgaria. She has been working as an Assistant Professor at the Oral Maxillofacial Surgery Department at the Medical University -Varna since 2009. She specialized in Oral Surgery in 2012. 